\title{
Learning TOC - Begins
}

\author{
Vishal Prajapati ${ }^{1}$, Shivani Champaneri ${ }^{2}$, Rahul Dhamecha $^{3}$, Janvi Sindha ${ }^{4}$, Dr. Sheshang Degadwala ${ }^{5}$ \\ ${ }^{1-4}$ U.G. B.E. Student Computer Engineering, Sigma Institute of Engineering, Bakrol, Gujarat, India \\ ${ }^{5}$ Head of Department Computer Engineering, Sigma Institute of Engineering, Bakrol, Gujarat, India
}

\begin{abstract}
Learning TOC - begins is a web application which is useful for Learning TOC (Theory of Computation). It covers hypothesis of the basic points with cases and it likewise has Exercise segment in which client can check different speculations for all intents and purposes. It likewise creates drawing of different cases. So the client can learn it adequately and additionally quick. Client can build FA of the string without anyone else and print or fare it for his task work. It has the office of Test to check his score and readiness work. So it is extremely valuable for client as exam arrangement. This Web Application is valuable for the educators and understudies and additionally different clients which are has a place with the Computer Science field. The fundamental reason for this web application is to pick up everything outwardly and graphically. It covers the listed topics given below- Regular Expression, Finite Automata, Context Free Grammar, Push Down Automata, Turing Machine, Exercise of the topics, Mock test.
\end{abstract}

Keywords: Theory of Computation, Finite Automata, Push Down Automata, Turing Machine, Context Free Grammar

\section{INTRODUCTION}

Learning TOC - Begins is a Virtual Lab of the subject Theory of Computation AKA TOC. It is a medium for students and teachers who want to learn by themselves or teach to others. As you know, like other virtual lab Learning TOC - Begins contains Theories and practicals with Animation but we also include live examples which is the step by step graphical representation of the examples and sums of TOC.

We have additionally included Test offices in our task which helps understudies for exam planning and the educators can likewise take trial of the entire class so it can help the two clients of the institute. Along these lines, general this undertaking give every vital segment which is vital for understudies and instructors to learn or educate.

\subsection{PURPOSE}

The primary of Learning TOC-Begins is to give a productive learning of the subject with illustrations. There are such a large number of framework which can clarify everything on the web yet we will here clarify everything with well ordered with visual liveliness so client can learn it or show it effortlessly.

\subsection{SCOPE OF SYSTEM}

Learning TOC-Begins is something like which will be helpful for every one of the understudies and instructors who need to learn or educate by his/her own. This Web Application is helpful to influence 
understudy to comprehend basics of the subjects and each idea with durable memory since representation technique stays additional time in the cerebrum contrast with Textual strategy.

\subsection{OBJECTIVES}

- To provide the fundamentals and detailed knowledge about this subject.

- To increase student's knowledge of this subject.

- To improve student's performance for examination.

- To help teachers to teach their student this subject.

- To provide facility of taking test for individual or group of students by teacher or student himself/herself.

\subsection{TECHNOLOGY AND LITERATURE REVIEW}

The Key Technologies used in developing the Learning TOC - Begins are:

1) Servers:

Microsoft SQL Server 2012

2) Clients:

- Microsoft Windows 7-8/ Windows XP with SP-3

- Mozilla Firefox

- Google Chrome

- Microsoft Edge

3) Tools:

- Microsoft Visual Studio 2010

- Notepad/Notepad++

- Microsoft Visio 2007

- Adobe Photoshop CS6

- Macromedia Flash 8

- Adobe Flash professional

We have used SQL server as the essential database. The utilization of SQL Server was done by exploring the upsides and drawbacks of various databases existing in the market.
SQL Server is a Relational Database Management System (RDBMS). As a database, it is an item thing whose basic limit is to store and recuperate data as requested by other programming applications. SQL Server joins better weight features, which in like manner helps in upgrading flexibility. It updated the requesting estimations and introduced filtered records.

SQL Server gives the graphical instruments you need to design, make, send, and control social databases, logical things, data change packs, replication topologies, declaring servers and reports, and notice servers. Additionally, SQL Server consolidates summon affect utilities to perform definitive assignments from the request incite

\section{SYSTEM ANALYSIS AND DESIGN}

\subsection{HARDWARE AND SOFTWARE} REQUIREMENTS (MINIMUM REQUIREMENTS TO RUN YOUR SYSTEM)

2.1.1. Hardware Requirements:

Table 1 Hardware Requirement

\begin{tabular}{|c|c|}
\hline COMPONENT & MINIMUM REQUIREMENTS \\
\hline PROCESSOR & Intel i6 $(1.6 \mathrm{GHz})$ or Higher \\
\hline RAM & $1.5 \mathrm{~GB}$ or Higher \\
\hline HDD & 6 GB or Higher \\
\hline
\end{tabular}

2.1.2.Software Requirements:

Table 2 Software Requirement

\begin{tabular}{|l|l|}
\hline \multicolumn{1}{|c|}{ COMPONENT } & \multicolumn{1}{|c|}{\begin{tabular}{c}
\multicolumn{1}{c|}{ TOOLS OR } \\
TECHNOLOGY
\end{tabular}} \\
\hline Operating System & Windows 7 or Higher \\
\hline Front End & $\begin{array}{l}\text { Asp.Net , JavaScript, } \\
\text { HTML, CSS and Flash } \\
\text { script }\end{array}$ \\
\hline Back End & $\begin{array}{l}\text { MS SQL server 2012 } \\
\text { (server less) }\end{array}$ \\
\hline Application & $\begin{array}{l}\text { Visual Studio 2015 } \\
\text { Macromedia Flash 8 } \\
\text { Microsoft Visio 2007 } \\
\text { Notepad/Notepad++ } \\
\text { Adobe Photoshop CS6 }\end{array}$ \\
\hline
\end{tabular}




\begin{tabular}{|l|l|}
\hline & Adobe Flash Professional \\
\hline Web browser & $\begin{array}{l}\text { Mozilla Firefox, Google } \\
\text { Chrome, Microsoft Edge }\end{array}$ \\
\hline
\end{tabular}

\subsection{SYSTEM ANALYSIS}

\subsubsection{STUDY OF CURRENT SYSTEM}

In current instruction framework, the subject is educate by both course reading and web strategy however in both technique they are constrained understudy to recall hypotheses and the measure of down to earth learning to be educated is less. Also the present framework is reliant on pen and paper, all that you learn by course book or web, you require a paper and a pen to amend it so it requires greater investment to peruse and compose and to comprehend and after you take in a few themes you can't certain to what extent it will be recollected in your psyche.

\subsubsection{PROBLEM AND WEAKNESS OF CURRENT SYSTEM}

- Time consuming because of pen and paper method

- Theoretical knowledge dependent

- Lengthy and confusing materials

\subsubsection{MYTHS ${ }^{[11]}$}

Teachers are often pressured to adopt totally virtual labs on the basis of certain common myths and misconceptions of the economics, utility, and scale of instructional technologies. In this section, I enumerate several of these myths and give counter-evidence for these misconceptions.

Myth \#1: Computer Activities should replace all other Developmental Biology Labs because of their Educational Advantages

Those making this contention oftentimes refer to the writing on demonstrating and Dewey's originations of experience, regularly blending both in a mélange of in part comprehended ideas (Schank and Cleary, 1995). In spite of the fact that Dewey unmistakably contended for the consideration of involvement in training (Dewey, 1938), late studies of PC intervened reproductions call attention to the false notions of expecting that PC models satisfy the requirement for encounter (Garrison and Scheckler, 2002; Waks, 2001). Quickly expressed, experience can be harsh, rigid, slack, or divided and instructive (Dewey, 1938). Experience profitable to training is persistent and intelligent. Numerous intelligent virtual exercises, regardless of how "reasonable," don't contain the components of vulnerability and progression that involvement with customary lab exercises give. Above all, in all instances of electronic activities, a man or individuals outlined the product that underlies the virtual lab. When they did this outline work, they chose parts of the natural circumstance to demonstrate. Along these lines, the model is settled and unequivocal and speaks to just a part of the whole framework. This incomplete model speaking to the whole circumstance (i.e., a synecdoche) is deceiving to understudies who don't comprehend the way toward demonstrating. In the experience of a customary lab, there is the vibe and possess an aroma similar to science, and once in a while even the peril of science. There is the vulnerability of what will happen or what will be seen, and there is the sharing between companions of differing perceptions and discoveries. Educators can react to the elements of the lab, associate materials to current social issues (See Gilbert and Fausto-Sterling, this issue), and interface companions to each other in ways that are liquid and opportune. That is the reason we can state that it is a wrong supposition.

\section{Myth \#2: Virtual Labs are a New Phenomenon}

Improvement of instructional advancements and helps is a continuum that could be stretched out back to the season of the creation of composed dialect or previously. I don't have to follow back that far to make the point that instructive innovations are not new, nor are they totally advanced. As new advancements, for example, the film projector, the radio, the $\mathrm{TV}$, and the $\mathrm{PC}$ were brought into instructive settings, they were praised as trades for 
vis-à-vis educators and schools (Connolly, 2001). What we ought to have learned as we advanced through the reception of these other instructive advances is that they are largely profitable guides to educating and realizing, that none of them are adequate to supplant the part of the educator in the typical goings on of the classroom and lab, and that numerous more innovations are yet to go along that will merit our consideration and thought.

\section{Myth \#3: Digital Labs save Money}

Very intelligent online classes can be as much as 30 times more costly than customary addresses (Rumble, 1993). Virtual labs will spare cash just in the event that they are not extremely intelligent and are utilized by an expansive number of understudies (Threlkeld and Brzoska, 1994). Not assessing the proceeding with support costs, taking a gander at expenses of low intuitiveness lessons, and expecting implausible economies of scale sustain the false notion of economical virtual labs. Are advancement costs high, as well as virtual labs require persistent upkeep. Some portion of the support is troubleshooting as the rigors of utilization uncover issues, changing substance as research uncovers distinctive systems, and routine moving down, looking after servers, safety efforts, repair and updates on workstations, and preparing of clients. What's more, advancements that serve 20 understudies sufficiently don't really scale up to serve bigger quantities of understudies. For vast classes, more powerful servers are required, more care staff, and more educators noting email and directing dialog gatherings, consequently generously expanding the expenses.

\section{Myth \#4: Students require Edutainment to remain}

\section{Engaged}

This is an exceptionally belittling perspective of understudies and one that isn't upheld. What draws in understudies is facing true issues in the lab (see Gilbert and Fausto-Sterling, this issue), participating in discourse with eager instructors, and being urged to associate their background with the goings on in the lab.
Myth \#5: Only Digital Labs are Interactive and Self-

\section{Directed}

Instructors at all levels and with fluctuating degrees of materials take part in request discovering that is intuitive and some of the time self-coordinated (National Research Council, 2000). As opposed to the digitization of the showing materials, it is the ability of the educator that brings intelligent material and self-coordinated exercises into the classroom. In an investigation of the utilization of the Internet for examining science (Feldman et al., 2000), the creators inferred that the core of request instructing is intelligent talk and suitable utilization of information. While the Internet conveys numerous more assets to the understudy, it is the gifted educator that guarantees that understudies connect with these rich assets and consider them properly.

\subsubsection{FEATURES OF NEW SYSTEM}

Our system has the features which other system also have but there are some features which are totally new and extra features in the competition with the old one. There are various features in the system like:

- Theories and quick summaries - which includes various theories related to subject.

- Live examples - to understand sums and theories, which includes examples of various problems of the subject with proper Animation.

- Practicals - to get the answer which causes problems to students, it can generate answer automatically by using algorithm.

- Mock Test - It is for exam preparation which includes test within a time limit so that students can be ready for examinations.

- Practice Test - for self-preparation which includes so many question with answers.

- Group test - It is to take the test of a group or class by teachers to know the progress as well as difficulties of each students and to prepare students for examination. 


\subsubsection{Details of Implementation}

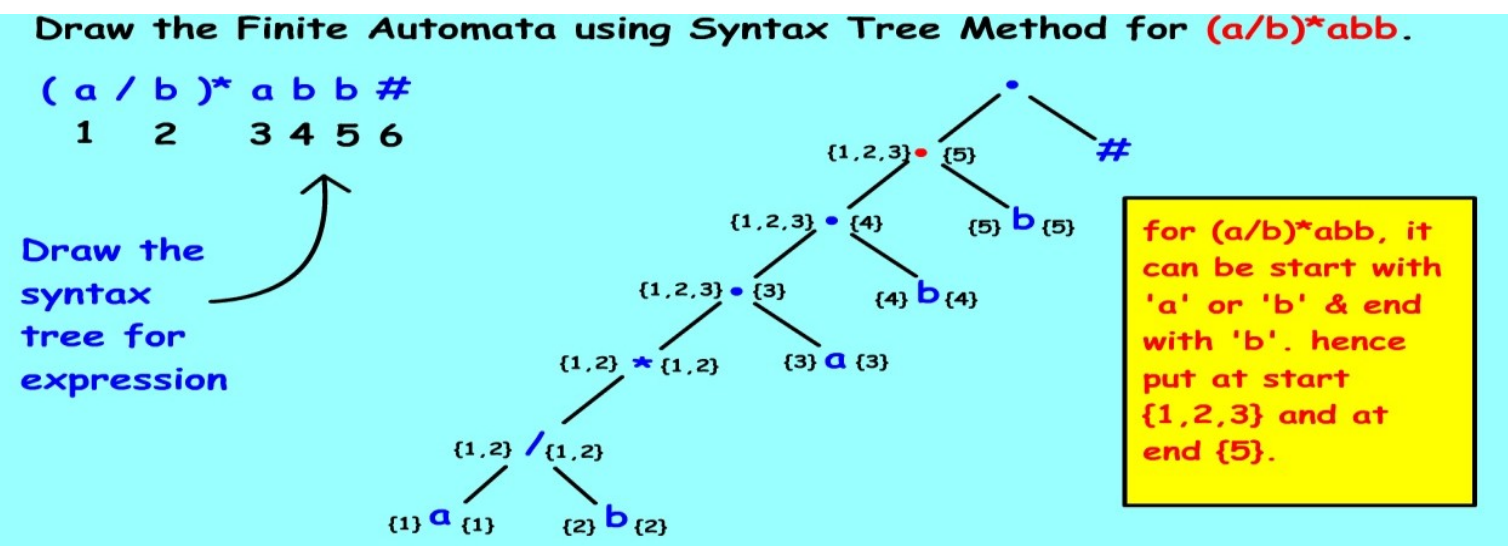

KI > ?

Figure 1 Syntax Tree Generation from Regular Expression

This picture represents the example of Finite Automata in which it gives syntax tree for the regular expression.

Draw the Finite Automata using Syntax Tree Method for $(a / b)^{*} a b b$. $(a / b)^{*} a b b \#$

123456

Answer :

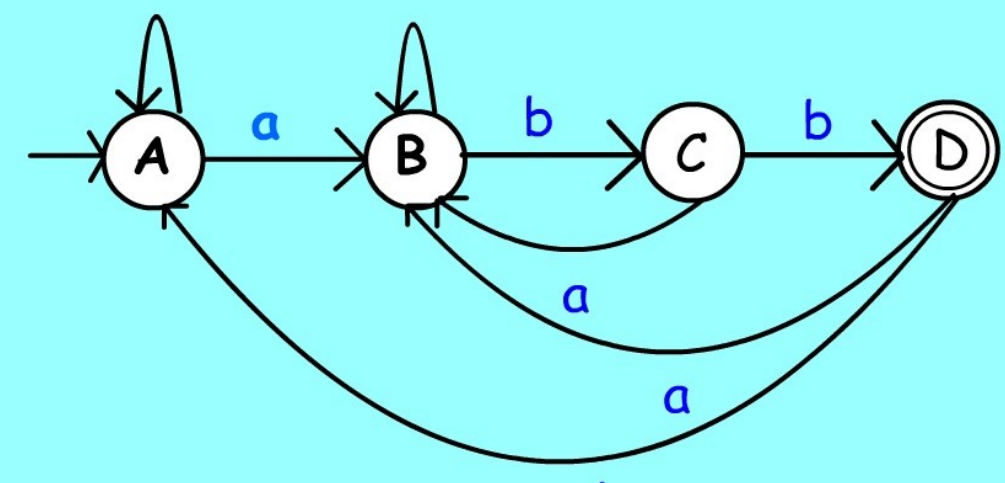

b

\section{KI Y ?}

Figure 2 Finite Automata Generation from Regular Expression

This picture represent the example of Finite Automata in which the Finite Automata will is given as a answer of the Regular Expression.

\section{SUMMARY OF PROJECT}

\subsection{ADVANTAGES}

- Logistics

- Low cost

- Open and Distance Learning

- Safety

- Education Benefits

\subsection{LIMITATION}

- This System useful only for the computer engineering students and teachers

- This system can't run offline.

- The system is only made for one subject - TOC (Theory of Computation).

- Skill Requirement

- Hardware and Networking requirement 


\subsection{FUTURE ENHANCEMENT}

- In future it will be possible to make different Virtual Labs for different subjects.

- In future we can make the system run offline.

- In future we can combine all subjects of a field and make Virtual Classrooms.

\section{CONCLUSION}

We will finish our venture work in view of utilizing programming building and framework investigation and configuration approach. Work that we have finished with preplanning booking related with time obliges and result situated advance in venture improvement. The Resulting Concluding Observations can add significant weight to Learning TOC - Begins. At first, there were some issue in regards to a few stages yet we have wanted to determine those issues. We have isolated our work in various stages and tackled issues and challenges.

\section{REFERENCES}

[1] Theory of Computation by John C. Martin

[2] The complete reference ASP.NET by Matthew MacDonald

[3] UML Distilled: A Brief Guide to the Standard Object Modelling Language(3rd Edition) by Martin Fowler

[4] Programming Microsoft ASP.net 4 by Dino Esposito

[5] http://vlab.co.in/ba_labs_all.php?id=2

[6] http://vlab.amrita.edu/?sub=78\&brch=256

[7] https://www.tutorialspoint.com/automata_theor y/index.htm

[8] https://www.tutorialspoint.com/microsoft_tech nologies_tutorials.htm

[9] https://en.wikipedia.org/wiki/Theory_of_compu tation

[10] https://www.youtube.com/results?search_query $=$ theory + of + computation
[11] Virtual labs: a substitute for traditional labs by REBECCA K. SCHECKLER, Department of Computer Science, Virginia Polytechnic Institute and State University, Blacksburg, Virginia, USA- Int. J. Dev. Biol. 47: 231-236 (2003)

[12] The role of Virtual Laboratories in Science Education by Huda Mohammad Babateen, Assistant Professor in Curriculum and Teaching Methods of Science Umm Al-Qura University Kingdom of Saudi Arabia. - IPCSIT vol.12 (2011) (C) (2011) IACSIT Press, Singapore. 